\title{
Artificial surfactant therapy for hyaline membrane disease
}

The demonstration that the lungs of infants who died with hyaline membrane disease (HMD) had abnormal surface properties ${ }^{1}$ prompted a number of attempts to treat the condition by administration of material with surface tension-lowering properties. The substance mainly used for this purpose during the period 1964-7 was synthetic dipalmitoyllecithin (DPL) prepared as an aerosol either in a mixture of propylene glycol and water or in a freon carrier. $^{23}$ The results were uniformly disappointing and treatment with surfactant was soon stopped in favour of nonspecific supportive measures. The efforts exerted by neonatologists for achieving adequate resuscitation at birth, warmth, control of acid base status, and improved methods of assisted ventilation and blood-gas monitoring seem to have led to improved survival of preterm infants with HMD. 4 Prenatal administration of steroids to induce maturation of the biochemical pathways for surfactant synthesis has also provided a possible means of preventing HMD in suitable cases. ${ }^{5}$ The possibility of prevention or treatment of HMD by instillation of artificial surfactant into the airways has however seemed sufficiently attractive to persuade several groups of workers to resume experimental studies in this area, particularly during the last 5 years. ${ }^{6-11}$ Fujiwara et al. ${ }^{12}$ have recently reported results after artificial surfactant treatment in a further small series of infants with HMD. In this issue (page 758), Morley et al. ${ }^{13}$ in a more cautious approach, compare the effects of administration of artificial with those of natural surfactant on the lungs of preterm rabbits.

At this stage there are two questions which the neonatologist may reasonably ask. Firstly, has there been a significant increase in knowledge and technical ability during the last decade which justifies further consideration of a previously discredited mode of treatment? Secondly, if treatment with artificial surfactant were to be introduced, what would be the realistic prospects for reduction in neonatal mortality and morbidity?

\section{Advances in knowledge of surfactant}

Pulmonary surfactant as isolated from mammalian lungs is a complex water-insoluble particulate material which consists principally of phospholipids, neutral lipids, and proteins ${ }^{14}$ although its composi- tion and molecular structure are not yet fully known. ${ }^{15}$ The protein content of natural surfactant precludes any possibility of using the material for treating human infants. ${ }^{13}$ Although $41 \%$ of surfactant may consist of DPL ${ }^{15}$ which has powerful surface tension-lowering properties in vitro, ${ }^{16}$ this substance in isolation does not possess all the physical characteristics required of a pulmonary surfactant. It absorbs very slowly to a surface, spreads slowly on a surface, and only undergoes a change from solid to liquid-crystalline state well above body temperature. ${ }^{15}$ The poor results of early attempts to treat infants suffering from HMD with this material are thus readily explicable. Recent studies on preparation of artificial surfactant have shown that these disadvantages of DPL can be overcome if it is mixed with phosphatidylglycerol in the correct proportions. ${ }^{13}$

An additional important advance has been the demonstration that the ability of natural surfactant to lower surface tension is greatly influenced by its physico-chemical state. If dispersed in water natural surfactant takes the form of a 'smectic mesophase' from which only a few molecules at a time can escape to contribute to a surface layer, whereas in the 'dry' form surfactant exists as a package of bimolecular sheets of phospholipids which are readily available to create a monomolecular surface layer. ${ }^{17}$

\section{Effectiveness of artificial surfactant treatment}

As a logical development from these advances Morley et al. ${ }^{13}$ have compared the effectiveness of a dry artificial surfactant with that of concentrated natural surfactant in improving the lung mechanics of preterm rabbit fetuses maintained on mechanical ventilation. Both natural and artificial surfactant improved the compliance of the rabbit lungs, even if administered after a period of spontaneous breathing. Lung aeration remained inadequate in surfactant-treated animals with distension of airspaces by oedema or unabsorbed fetal lung liquid. Bronchiolar epithelial damage, attributed to mechanical ventilation, was seen in all fetuses except one. The experiments were of short duration and provide no evidence on the ability to influence survival. Fujiwara et al..$^{12}$ have used as an artificial surfactant 
a mixture of synthetic DPL and phosphatidylglycerol added to a Folch extract of minced beef lung. ${ }^{18}$ They report the results of administering this material as a saline suspension via an endotracheal tube to 10 infants with severe HMD at ages of 4-33 hours. There was rapid clinical improvement with increased $\mathrm{PaO}_{2}$, reversal of acidosis and systemic hypotension, and rapid initial clearing of radiological abnormalities in most infants. Two infants died (one of tracheo-oesophageal fistula and the other of sepsis). One of the dead infants and one survivor had bronchopulmonary dysplasia. All survivors in this series developed signs of patent ductus arteriosus, which Fujiwara et al. believe to have resulted from chronic pulmonary oedema with left-to-right shunts. A worrying feature of this work is the use, for treating babies, of an artificial surfactant mixture which apparently contains $2 \%$ of foreign protein. Fujiwara et al. claim to have established the safety of this material as a drug by extensive studies, and refer to its lack of toxicity when injected intraperitoneally in experimental animals.

\section{Prospects for use of artificial surfactant in infants}

If one assumes that the technical problems of developing a safe form of artificial surfactant which can be readily applied through an endotracheal tube are overcome, it is necessary to decide which infants with HMD should be treated, at what stage of the illness, and how the results should be assessed.

It must be stressed that the results of current management of HMD in neonatal intensive care units are so good that there is no place for introduction of any new mode of treatment without properly controlled clinical trials. If, as Morley et al..$^{13}$ suggest, surfactant needs to be administered before the first breath, a very large trial would be needed as many of the infants subjected to such treatment would not have been likely to develop HMD.

Very few babies now die of uncomplicated HMD. Any improved outlook for infants treated with surfactant will therefore have to be related to reduced morbidity and mortality from a whole range of associated conditions including pneumothorax, bronchopulmonary dysplasia, intraventricular haemorrhage, and necrotising enterocolitis.

Artificial surfactant therapy may yet prove to have a useful role in treatment of HMD, but this is an area of medicine where advance is most likely if paediatricians can learn to hasten slowly.

\section{References}

1 Avery E M, Mead J. Surfact properties in relation to atelectasis and hyaline membrane disease. Am J Dis Child 1959; 97: 517-23.
2 Robillard E, Alarie Y, Dagenais-Perusse P, Baril E, Guilbeault A. Microaerosol administration of synthetic $\beta$ - $\gamma$-dipalmitoyl-L- $\alpha$-lecithin in the respiratory distress syndrome. Can Med Assoc J 1964; 90 : 55-7.

3 Chu J, Clements J A, Cotton E K, Klaus M H, Sweet A Y, Tooley W H. Neonatal pulmonary ischemia. I. Clinical and physiological studies. Pediatrics 1967; 40: 709-82.

4 Roberton N R C. Management of hyaline membrane disease. Arch Dis Child 1979; 54: 838-44.

5 Liggins G C, Howie R N. A controlled trial of antepartum glucocorticoid treatment for prevention of respiratory distress syndrome in premature infants. Pediatrics 1972; 50: 515-25.

- Enhörning G, Robertson B. Lung expansion in the premature rabbit fetus after tracheal deposition of surfactant. Pediatrics 1972; 50: 58-66.

7 Ikegami M, Hesterberg T, Nozaki M, Adams F $H$. Restoration of lung pressure-volume characteristics with surfactant. Comparison of nebulization versus instillation and natural versus synthetic surfactant. Pediatr Res 1977; 11: 178-82.

8 Adams F H, Towers B, Osher A B, Ikegami M, Fujiwara T, Nozaki M. Effects of tracheal instillation of natural surfactant in premature lambs. I. Clinical and autopsy findings. Pediatr Res 1978; 12: 841-8.

- Cutz E, Enhörning G, Robertson B, Sherwood W G, Hill D E. Hyaline membrane disease. Effect of surfactant prophylaxis on lung morphology in premature primates. Am J Pathol 1978; 92: 581-94.

10 Enhörning G, Hill D, Sherwood G, Cutz E, Robertson B, Bryan C. Improved ventilation of prematurely delivered primates following tracheal deposition of surfactant. Am J Obstet Gynecol 1978; 132: 529-36.

11 Nilsson R, Grossmann G, Robertson B. Lung surfactant and the pathogenesis of neonatal bronchiolar lesions induced by artificial ventilation. Pediatr Res 1978; 12: 249-55.

12 Fujiwara $T$, Maeta $H$, Morita T, Watabe $Y$, Chida $S$, Abe T. Artificial surfactant therapy in hyaline membrane disease. Lancet 1980; i: 55-9.

13 Morley C, Robertson B, Lachmann B, et al. Artificial surfactant and natural surfactant. Comparative study of the effects on premature rabbit lungs. Arch Dis Child 1980; 55: 758-65.

14 Clements J A, Tooley W H. Kinetics of surface-active material in the fetal lung. In: Hodson W A, ed. Development of the lung. New York: Marcel Dekker, 1977: 349-66.

15 Strang L B. Neonatal respiration: physiological and clinical studies. Oxford: Blackwell, 1977: 94-9.

16 Brown E S. Isolation and assay of dipalmitoyl lecithin in lung extracts. Am J Physiol 1964; 207: 402-6.

17 Morley C J, Bangham A D, Johnson P, Thorburn G D, Jenkin G. Physical and physiological properties of dry lung surfactant. Nature $1978 ; 271$ : 162-3.

18 Fujiwara T, Tanaka Y, Takei T. Surface properties of artificial surfactant in comparison with natural and synthetic surfactant lipids. IRCS Med Sci 1979; 7: 311.

J S WIGGLESWORTH

Department of Paediatrics and Neonatal Medicine, Hammersmith Hospital,

Du Cane Road,

London W12 OHS 